Article

\title{
An Evaluation of Radarsat-1 and ASTER Data for Mapping Veredas (Palm Swamps)
}

\section{Philippe Maillard ${ }^{1} *$, Thiago Alencar-Silva ${ }^{1}$ and David A. Clausi ${ }^{2}$}

1 Departamento de Cartografia, Universidade Federal de Minas Gerais - UFMG, Belo Horizonte, Minas Gerais, Brazil, 31270-901; E-Mail: thiago-alencar@uol.com.br

2 Systems Design Engineering, University of Waterloo, Waterloo, Ontario, Canada, N2L 3G1; E-Mail: dclausi@engmail.uwaterloo.ca

* Author to whom correspondence should be addressed; E-Mail: philippe@ cart.igc.ufmg.br; Tel.: +55-31-3409-5427; Fax: +55-31-3409-5410

Received: 6 August 2008; in revised form: 10 September 2008 / Accepted: 22 September 2008 / Published: 26 September 2008

\begin{abstract}
Veredas (palm swamps) are wetland complexes associated with the Brazilian savanna (cerrado) that often represent the only available source of water for the ecosystem during the dry months. Their extent and condition are mainly unknown and their cartography is an essential issue for their protection. This research article evaluates some of the fine resolution satellite data both in the radar (Radarsat-1) and optical domain (ASTER) for the delineation and characterization of veredas. Two separate approaches are evaluated. First, given the known potential of Radarsat-1 images for wetland inventories, the automatic delineation of veredas is tested using only Radarsat-1 data and a Markov random fields region-based segmentation. In this case, to increase performance, processing is limited to a buffer zone around the river network. Then, characterization of their type is attempted using traditional classification methods of ASTER optical data combined with Radarsat-1 data. The automatic classification of Radarsat data yielded results with an overall accuracy between 62 and 69\%, that proved reliable enough for delineating wide and very humid veredas. Scenes from the wet season and with a smaller angle of incidence systematically yielded better results. For the classification of the main vegetation types, better results (overall success of 78.8\%) were obtained by using only the visible and near infrared (VNIR) bands of the ASTER image. Radarsat data did not bring any improvement to these classification results. In fact, when using solely the Radarsat data from two different angle of incidence and two different dates, the classification results were low
\end{abstract}


$(50.8 \%)$ but remained powerful for delineating the permanently moist riparian forest portion of the veredas with an accuracy better than $75 \%$ in most cases. These results are considered good given the width of some types often less than $50 \mathrm{~m}$ wide compared with the resolution of the images $(12.5-15 \mathrm{~m})$. Comparing the classification results with the Radarsat-generated delineation allows an understanding of the relation between synthetic aperture radar (SAR) backscattering and vegetation types of the veredas.

Keywords: Radarsat, Unsupervised Classification, Markov Random Fields, Wetlands, Palm swamps, ASTER, Supervised Classification, Vegetation types.

\section{Introduction}

As wetlands, veredas (palm swamps) bear an essential role in the environment by enhancing water quality, reducing flood damage, sequestrating carbon and supporting a disproportional part of the biodiversity [1-3]. Being associated with the cerrado (Brazilian savanna), veredas are also frequently the only source of perennial water supply during the dry months of the year (in the cerrado of Minas Gerais the dry season can last for six to eight months) $[4,5]$.

Figure 1. Photographs illustrating the different types of veredas (a) as seen from the ground and (b) from the air: A - Wooded Savanna, B - Wet meadow, C Shrubland/Riparian forest, D - Buriti palms.

(a)

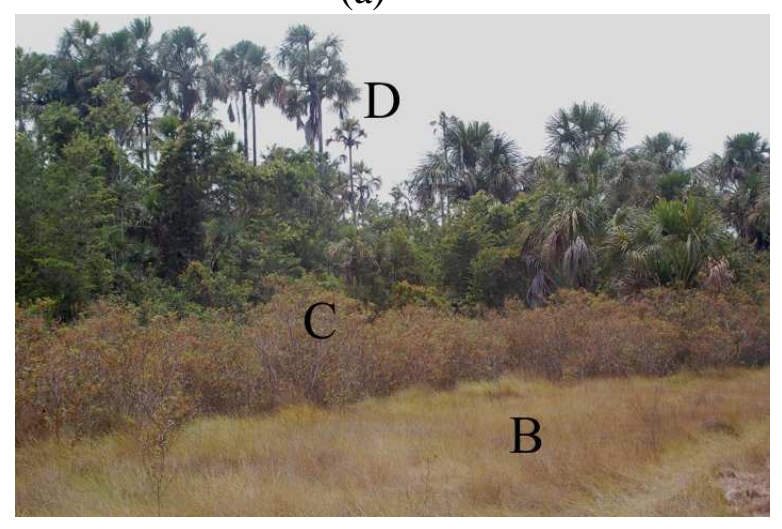

(b)

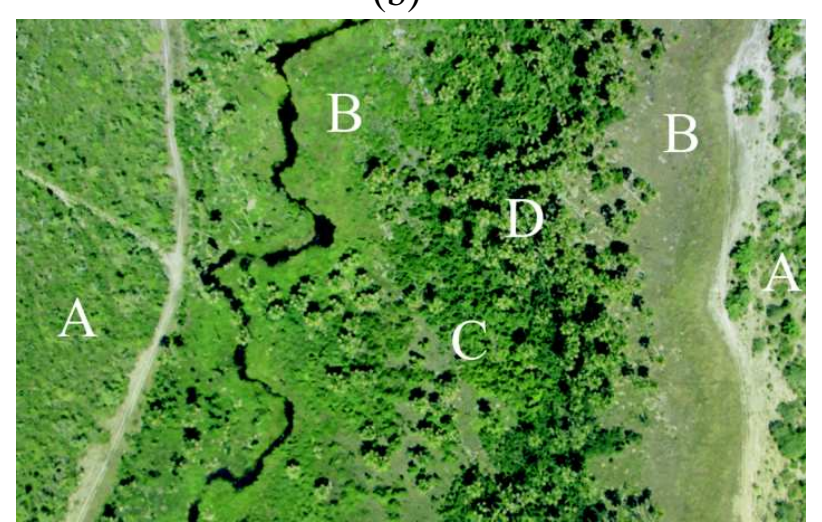

Veredas present varying types, ranging from wet meadows to riparian forest and are associated with the presence of Buriti palms (Mauritia flexuosa L.f., see Figure 1). Although their aspect can vary significantly, typical veredas are relatively narrow landscape features that follow a mostly intermittent stream that can either have a diffuse or well-defined channel. Their width can vary from tens of meters to a few hundred. While cerrado is a mostly open wooded savanna formation adapted to semiarid conditions, veredas are closed riparian formations characterized by hydromorphic soils with high organic content. From the contact with cerrado vegetation towards the lowest point of the valley, typical veredas show the following sequence of types: grassland (wet meadows), shrubs and trees often dominated by Mauritia flexuosa. 
They form under very specific hydrological and geomorphological conditions; veredas are riparian zones of a mostly flat topography characterized by the superposition of a pervious rock layer over an impervious one causing the aquifer to surface during a sufficiently long part of the year for hydromorphic soils to form $[4,5]$.

The distribution of the different types are ruled by the availability of water; the central part is usually saturated all-year-round, whereas the marginal wet meadows suffer from strong fluctuations of the water table, causing the soil to be either saturated or flooded from November to March or dry from April to October [4]. As such, veredas can be considered, in the long term, as "barometers" of the aquifer. For example, excessive irrigation in nearby agricultural projects on very sandy soils can lower the water table and result in the irreversible degradation of veredas. Conversely, the construction of dams causing permanent flooding will have a similar effect causing the death of the veredas.

With the rapid conversion of cerrado to agro-pastoral activities veredas (Cerrado is the most threatened biome of Brazil with a conversion rate exceeding that of the Amazon forest [6].) are increasingly threatened. Despite being protected by the Brazilian legislation, veredas in numerous regions of Minas Gerais [with an area of $587.150 \mathrm{~km} 2$, Minas Gerais is the fourth largest state in Brazil and is dominated by the cerrado $(\approx 60 \%)$, for which veredas represent one of its most important source of perennial water during the dry months] already show signs of advanced degradation. However, the actual degree of this degradation is still unknown as is the true extent of veredas in Minas Gerais [5].

\subsection{The use of remote sensing for wetland mapping}

The three primary methods of wetlands inventory are on-site field work, photo-interpretation of aerial photography and digital image processing of satellite imagery. The first two have the disadvantage of a relatively long time lag between data acquisition and map production [7]. Assuming a timely processing and interpretation, satellite remote sensing is considered the only practical method for mapping and monitoring wetlands [8]. It has been reported [9] that research is needed in the field of remote sensing to assess total wetland resource habitats, detect changes at large spatial scales and produce standardized approaches to inventory and information dissemination. For example, [10, 11] found that Landsat TM data showed a good capacity to estimate the extent of wetlands in various regions of the globe. Others have found that the presence of a dense canopy makes it difficult to separate wetlands from other forest types [12]. In the specific case of veredas, [13] have found that they often cannot be separated from other riparian formation not classified as wetlands. Baker et al. [7] have attained high classification success (> 85\%) using Landsat ETM+ in combination with topographic and soil data.

Optical data have the additional limitation of not permitting the acquisition of imagery under cloudy conditions or at night. In that perspective, synthetic aperture radar (SAR) offers a promising approach, since it is unaffected by clouds or illumination conditions. SAR also has the ability (conditioned by the frequency used) to penetrate the canopy and yield information about the ground. The frequencies used by radar systems, ranging roughly from $300 \mathrm{MHz}$ to $30 \mathrm{GHz}$ (or wavelengths of respectively $1 \mathrm{~m}$ to 1 $\mathrm{cm}$ ), interact with different parts of the vegetation. While with longer wavelengths (P- and L-band) 
scattering and attenuation result mainly from interaction with trunks and large branches, shorter wavelengths from the $\mathrm{K}$ and $\mathrm{X}$ bands interact primarily with leaves. Mid-range wavelengths like the $\mathrm{C}$ and $\mathrm{S}$ bands interact with a combination of leaves and branches [14].

\subsection{Interaction between radar backscatter and wetland vegetation}

Reflection of radar pulses is generated by a discontinuity in the dielectric constant of the surface, the larger the difference, the larger the reflection. The roughness at the wavelength scale (a few centimeters) being a function of the frequency, and orientation of the surface govern the amount of energy scattered back to the side-looking antenna. A water surface has a high dielectric constant, but if it has a smooth surface, it will reflect all the energy away from the antenna. Conversely, dry soil and dry bark of trees have a relatively low dielectric constant and most of the energy is transmitted or absorbed leaving a backscatter of relatively low magnitude [15]. Regardless, since energy is scattered in all directions, a significant portion is still returned towards the antenna. For soil and vegetation, it is primarily the moisture content that increases the dielectric constant and provide high radar pulse reflection [16]. Combined with a rough surface having many vertical structures, high dielectric constant of humid surfaces provide strong signal return to the radar antenna which translates into bright features on the radar image.

The fact that radar backscattering is very sensitive to moisture is a very useful characteristic for wetland mapping. With some exceptions like mud flats, humid or saturated soil of wetlands are usually well vegetated and have a relatively rough surface that will strongly scatter the microwave pulses in all directions yielding a relatively high signal return [17]. A third SAR phenomenon is frequently observed in wetland environments when a vegetated surface is flooded; the pulses are first reflected away by the smooth flooded ground then back to the antenna by the perpendicular vegetation structure. The combination of the two perpendicular surfaces act as a corner reflector that causes the radar pulses to bounce back at the antenna, a phenomenon called double bounce $[8,18]$. This is especially true for longer wavelengths (L- and P-bands). In the case of shorter wavelength like C-band (5,3 GHz or $\lambda=5,6$ $\mathrm{cm})$ the increase of backscattering appears to be primarily due to increased moisture combined with a rough canopy structure. Conversely, in wetlands with no woody plants, the increase in specular scattering caused by standing water tends to decrease radar backscattering [14]. This situation is likely to happen in the grassland that margin the veredas during the high wet season when they are flooded. These mechanisms are illustrated and explained in Figure 2.

SAR data has proven its utility for mapping wetland and flooded forests extents [19], but its ability to discriminate between vegetation type and form is mainly dependent on the use of multi-date, multifrequency or multi-polarization radar data or a combination of these multiple data sets [14]. Studies have shown that using Radarsat-1 in combination with optical Landsat data can significantly improve land cover classification [20-22]. However, it should be mentioned that these studies were aimed at improving land-cover mapping from Landsat data with a $30 \mathrm{~m}$ resolution cell and that radar derivative (mostly texture features) were used. Generally speaking, unless one would want to separate very different features (wetland vs. forest vs. urban), optical remote sensing is still preferable to singledate/frequency/polarization radar data for such applications as classification of vegetation types and, 
only when integrated with optical data has a single SAR image been found to bring a significant improvement to the classification of vegetation [23].

Figure 2. The main mechanisms governing the interaction between SAR C-band signal and a vereda. Legend: 1) wooded savanna, 2) intermittently dry grasses, 3) shrub, 4) trees with a predominance of 5) Mauritia flexuosa L.f. and 6) permanently wet grasses, i) dry sandy soil , ii) hydromorphic, almost permanently moist soils, iii) the aquifer is permanently close to the surface. In A) the dry wooded savanna and dry soils have a low dielectric constant but a high scattering potential. In B) the grasses have a relatively high scattering power and can have a high dielectric constant when wet or when the soil is saturated. In C) and E) the shrub and trees growing on hydromorpic soils are good scatterers and are moist with a high dielectric constant. In D) the riparian forest is a good scatterer with a high dielectric constant and can act as a corner reflector on its margin. Finally, in F) flooded grasses cause most of the signal to be reflected away from the SAR antenna.

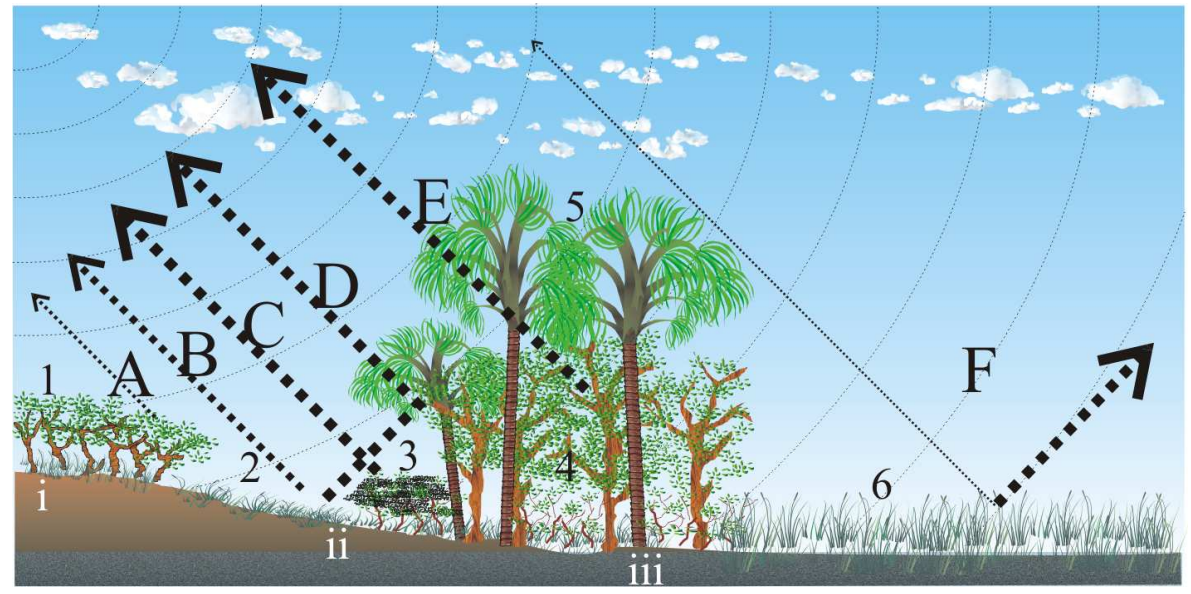

\subsection{Objectives and organization of the article}

The objective of this research was to evaluate the potential of Radarsat-1 (SAR) and Advanced Spacebone Thermal Emission an Reflection Radiometer or ASTER (optical) satellite data for delineating and characterizing veredas at the $10 \times 10-30 \times 30 \mathrm{~m}$ scale (A range of resolution cells, generally considered as "fine" [8] but not "high".). Radarsat-1 was the SAR of choice for its recognized potential for mapping wetlands and flooded forests [14, 19, 24-27]. ASTER optical data from the Terra satellite were selected as an improved substitute to Landsat [28] in terms of spatial resolution.

Unless strongly filtered or when texture derivatives are used, traditional pixel-based classification algorithms do not perform well with single-date/frequency/polarization SAR data [20, 29]. MRF-based (Markov random field) classification algorithms have yielded good results in other SAR image classification applications [30, 31]. The algorithm developed by [31] has successfully been applied by the authors in a sea ice classification application [32] and has yielded promising results for palm swamp delineation [33]. The same algorithm is being tested here for the unsupervised delineation of veredas using the hydrographic network as a starting point. Because veredas are always associated with 
the hydrographic network, this knowledge has been used to limit processing to a buffer zone on either side of the streams. It is hypothesized that this measure contributes to reduce class confusion and to increase classification success rate.

Conversely, classical pixel-based classification algorithms usually work well with optical data or combinations of optical and SAR data (or derivatives) in the selected range of spatial resolution. Different combinations of ASTER bands and Radarsat-1 images were evaluated for the supervised classification of the different types encountered in typical veredas as a means of characterization.

Finally, the results from the SAR and optical data are compared by spatially intersecting their results to assess the potential of Radarsat data and the unsupervised MRF-based classification approach for delineating veredas. This approach helped understand what types were actually captured by the SAR data and the MRF-based unsupervised classification. The use of two different angles of incidence at two different phenological times brings further insight on the optimal SAR C-band image parameters.

\section{Materials and Methods}

\subsection{Study Area}

The study area is situated along the course of the Peruaçu river in Northern Minas Gerais - Brazil, in a region called Chapadão das Gerais. The area was chosen for being one of the rare well preserved regions of the Brazilian savanna having ideal environmental conditions for the research (being a protected area) and having some of the longest veredas areas of the country (Figure 3). The study area covers about $540 \mathrm{~km}^{2}$ and about 50 linear $\mathrm{km}$ of veredas. It also completely encloses the Veredas do Peruaçu State Park $\left(\approx 31 \mathrm{~km}^{2}\right)$. The Peruaçu river is a tributary of the São Francisco river, the third largest watershed of Brazil. The region's bedrock is composed of a layer of sandstone (usually highly weathered) over carbonates from the superior Proterozoic. The topography is mostly flat and slopes are very smooth. The climate is semiarid, with an average temperature of over $25^{\circ} \mathrm{C}$. Precipitation averages $124 \mathrm{~mm}$ per month between October and April and less than $2 \mathrm{~mm}$ between May and September [34].

\subsection{Imagery}

Four Radarsat-1 images were acquired for the present study from a "Data for Research Use" (DRU) project promoted by the Canadian Space Agency (C CSA - http://www. space/gc/ca). The images were acquired in the "standard beam" mode for two distinct periods corresponding to the two main phenological seasons; April or the end of the wet season when the soil is saturated and September or the end of the dry season when the hydrological balance is at its lowest. For each period, two images of different incidence angles (the angle of incidence is the angle between the line of sight from the radar to the ground and the vertical direction) were acquired: S2 with $24^{\circ}$ to $31^{\circ}$ for the near and far range respectively and S6 $\left(41^{\circ}\right.$ to $\left.46^{\circ}\right)$. The image pixels have a spatial resolution of $12.5 \times 12.5 \mathrm{~m}$ and a radiometric depth of 16 bits. SAR images with these characteristics were ordered in an effort to assess the best period/incident angle for delineating the veredas. It was expected that S6 scenes would be 
more affected by volume scattering and vegetation structure consequently $[35,36]$ and that the S2 scenes would respond more to direct scattering and soil moisture.

Figure 3. Location of the study area.

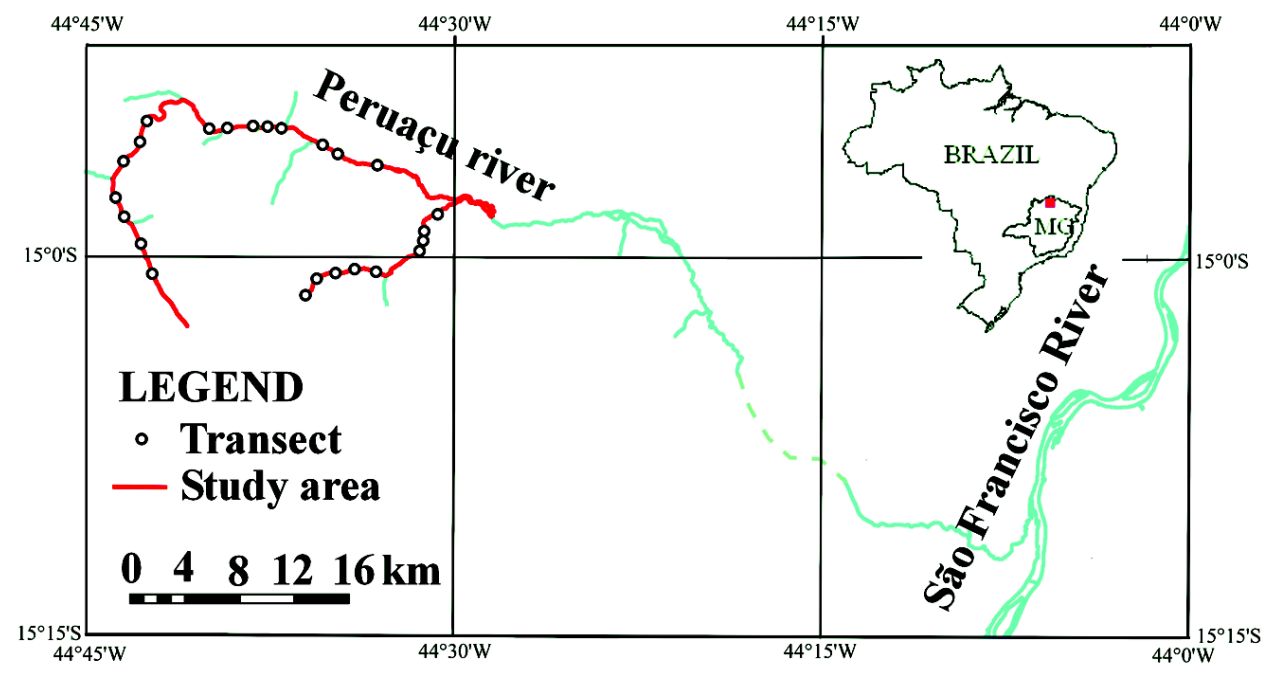

One ASTER image from the Terra/EOS AM-1 satellite (http://terra.nasa.gov) of the study area was acquired on 21 August 2006. The ASTER instrument is composed of three subsystems: VNIR (visual and near infrared) with three bands (green $0.52-0.60 \mu \mathrm{m}$, red 0.63-0.69 $\mu \mathrm{m}$ and infrared 0.76-0.86 $\mu \mathrm{m}$ ) and $15 \mathrm{~m}$ ground resolution, SWIR (shortwave infrared ranging from $1.6 \mu \mathrm{m}$ to $2.43 \mu \mathrm{m}$ ) and $30 \mathrm{~m}$ ground resolution and TIR (thermal infrared) with a resolution of $90 \mathrm{~m}$. To take full advantage of the fine ground resolution of the VNIR and SWIR subsystems, bands from the TIR were not used in this study. Even though TIR could prove useful since veredas are expected to be cooler than the surrounding savanna, the $90 \mathrm{~m}$ resolution was considered too broad for the application at hand. Some of the SWIR bands (2, 3 and 5) were included in addition to the three VNIR bands.

All four SAR images and the ASTER image were geometrically corrected using in situ ground control points collected with a navigation GPS and image-to-image based on a geo-referenced Landsat ETM+ panchromatic band with a ground resolution of $15 \mathrm{~m}$. Since the relief is mostly flat, displacement effects caused by the incidence angle were almost negligible and all five images had mean square errors below $20 \mathrm{~m}$. Speckle noise was not filtered from the SAR images because speckle noise algorithms tend to erode class boundaries when unsupervised segmentation is applied, reducing the quality of the classification [31]. A standard radiometric correction was applied to the three VNIR bands of the ASTER image [37].

\subsection{Field Work and Ground Truth Data}

Veredas are by nature difficult to access by land. Except for the usual fringe of grass on both sides, the center is either flooded or saturated and the vegetation is very dense. Our field campaign consisted of a series of 24 transects made at intervals being multiples of 500 meters approximately. The length of the transects ranges from $142 \mathrm{~m}$ to $598 \mathrm{~m}$ with an average of $299 \mathrm{~m}$. Each transect was started and ended with 40 to $50 \mathrm{~m}$ in the savanna type. The vereda was crossed by foot and every change of type in 
the vegetation was recorded and positioned using a navigation global positioning system (GPS). Despite the imprecision of the navigation GPS estimated at about $10 \mathrm{~m}$, all transect were geometrically consistent, in terms of alignment, and a good visual match was obtained with both SAR and optical imagery. These transects were plotted and incremented with vegetation artwork as showed in Figure 4. The transects were rasterized to match the size of the resolution cells of both image types (Radarsat-1 at $12.5 \mathrm{~m}$ and ASTER at $15 \mathrm{~m}$ ). Other more traditional (small areas) training/validation sites were also collected in locations of easier access such as in the savanna and sandy areas.

Figure 4. Example of graphically enhanced transect across a narrow stretch of vereda. Note the buriti palms in the center, bordered by shrub, grasses and wooded savanna successively.

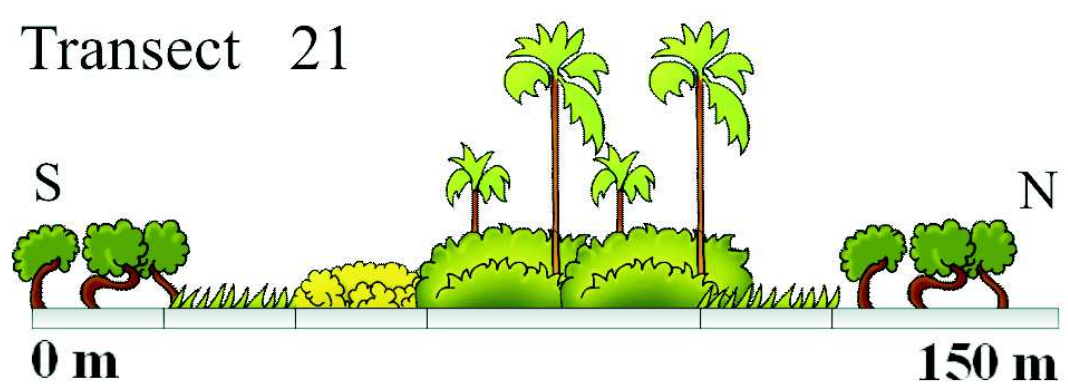

Two sets of reference data were created from these transects. In the first one, the different types were reclassified in two classes: 1) vereda and 2) non-vereda to assess the success rate of the classification of the Radarsat images in delineating the extent of the veredas. An alternate set was created where the meadow (grass) type was removed from the vereda class and added to the nonvereda class since it was not clear, from visual interpretation of the Radarsat images, in which class it would fall. For the second set, the original reference vertices were converted into reference pixels of 15 meters for the classification of the ASTER image into the different types (see Table 1 for their description). In both cases, pixels located at transition points (between different types for ASTER or between vereda and non-vereda for Radarsat) were eliminated to keep only the pixel unequivocally containing a single vegetation class. Half of these reference pixels were randomly selected for training while the other half was reserved to validate the classification results. The different classes recorded are described in Table 1.

Botanical material was also collected for identification and samples of soil were hermetically bagged for soil moisture to be measured in laboratory. The soil moisture data was not collected at the same time as the image acquisition but at the beginning of the dry season and at least two weeks after the last precipitation event. Although not coincident in time, these data are still helpful to understand the difference between the different vegetation types and their respective soil.

\subsection{Hydrography-based buffering}

Knowing that veredas are always found along streams (most authors consider that veredas necessarily follow the natural hydrographic network), the hydrographic network was used to create a buffer zone to limit the regions used for processing. Veredas are rarely wider than about 500 meters so 
a 2,000 meter-wide corridor can easily account for all imprecisions in the hydrographic network of 1:100,000 topographic maps and include the widest of vereda. Medium scale topographic maps are available in digital form for most of Brazil and although most of them are outdated (> 25 years old), dislocation errors are likely to fall well within the $1,000 \mathrm{~m}$ on both side of the streams. Such process was done using the buffering tool of a standard geographic information system (GIS) to create a mask that was later applied to all Radarsat image data.

Table 1. Class name and description of vegetation type of the veredas and surrounding areas.

\begin{tabular}{|c|c|}
\hline Class name & Description \\
\hline Grassland & $\begin{array}{l}\text { A relatively narrow }(<50 \mathrm{~m}) \text { band of grass usually inserted } \\
\text { between the savanna and the shrubland or the riparian forest; }\end{array}$ \\
\hline Shrub & $\begin{array}{l}\text { A narrow band of shrub that may or may not be present between } \\
\text { the meadow and the trees; }\end{array}$ \\
\hline Riparian forest & $\begin{array}{l}\text { A relatively dense canopy of trees with emerging buriti palms } \\
\text { and having a width that can vary from less than fifty meters to a } \\
\text { few hundreds of meters; }\end{array}$ \\
\hline Sparse wooded savanna & $\begin{array}{l}\text { A sparse community of small trees }(<5 \mathrm{~m}) \text { and shrub with } \\
\text { frequent patches of bare soil; }\end{array}$ \\
\hline Dense wooded savanna & $\begin{array}{l}\text { A dense community of small trees }(<7 \mathrm{~m}) \text { and shrub with a } \\
\text { continuous canopy; }\end{array}$ \\
\hline Bare soil (sand) & $\begin{array}{l}\text { Areas of very little vegetation (usually grasses and some shrub) } \\
\text { characterized by loose sand; }\end{array}$ \\
\hline Open water & $\begin{array}{l}\text { Class almost exclusively represented by small lakes but might } \\
\text { include some open water areas within the veredas. }\end{array}$ \\
\hline
\end{tabular}

\subsection{Delineating the veredas using the Radarsat Images}

Classification of the Radarsat images was performed in two steps: 1) unsupervised classification and 2) labeling. The unsupervised classification was done using the MAMSEG (Modified Adaptative Markov random fields SEGmentation) algorithm, developed by [31] and based on Markov random fields (MRF). The advantage of MRF models lies in their inherent ability to describe simultaneously the local spatial context (the relationship between neighboring pixels) and the feature characteristics of each segment (from the distribution of spectral values for example). This is most appropriate since pixels of a satellite image cannot be considered independent processes but are spatially correlated. The MAMSEG algorithm has proven to be a powerful classification tool for both artificially textured images and SAR sea ice images [31, 32].

The MRF model [38] assumes that the conditional probability of a pixel given its neighbors is equal to the conditional probability of that pixel given the rest of the image. This makes it possible to consider every pixel within its neighborhood as an independent process facilitating its mathematical 
modeling [39]. Within a Bayes rule framework, the conditional probability of a pixel belonging to a given class (or segment in the unsupervised case) $\mathrm{Y}_{\mathrm{i}}$ is equal to:

$$
P\left(Y_{i} \mid x\right)=\frac{p\left(x \mid Y_{i}\right) P\left(Y_{i}\right)}{\sum_{i}\left[p\left(x \mid Y_{i}\right) P\left(Y_{i}\right)\right]}
$$

P where $\boldsymbol{p}\left(\boldsymbol{x} \mid \boldsymbol{Y}_{\boldsymbol{i}}\right)$ is the conditional distribution of vector $x$ given class/segment $\boldsymbol{Y}_{\boldsymbol{i}}$ and $\boldsymbol{P}\left(\boldsymbol{Y}_{\boldsymbol{i}}\right)$ is the prior probability of the $\boldsymbol{Y}_{i}$ class. Suppose that the energy associated to the prior probability is $\mathrm{E}_{\mathrm{r}}$ and that $\mathrm{E}_{\mathrm{f}}$ represents the energy of the spatial context $\boldsymbol{p}\left(\boldsymbol{x} \mid \boldsymbol{Y}_{\boldsymbol{i}}\right)$, then the general energy formula is given by [40]:

$$
\boldsymbol{E}=\boldsymbol{E}_{\boldsymbol{r}}+\alpha \boldsymbol{E}_{f}
$$

where $\mathrm{E}_{\mathrm{f}}$ is the energy form of feature vector $f$ having $\mathrm{k}$ dimensions. Assuming a Gaussian distribution $\mathrm{E}_{\mathrm{f}}$ can be modeled as:

$$
\boldsymbol{E}_{f}=\sum_{s, m=Y_{s}}\left\{\sum_{k=1}^{K}\left[\frac{\left(f_{s}^{k}-\mu_{m}^{k}\right)^{2}}{2\left(\sigma_{m}^{k}\right)^{2}}+\log \left(\sqrt{2 \pi \sigma_{m}^{k}}\right)\right]\right\}
$$

where $\mu_{\mathrm{m}}$ and $\sigma_{\mathrm{m}}$ are the mean and standard deviation of $m$ th class in the $k$ th feature vector. $\mathrm{E}_{\mathrm{r}}$ represents the energy of the labels (classes) in the neighborhood of the pixel being analyzed based on a system of clique (generally pairs or triplets of contiguous pixels):

$$
\boldsymbol{E}_{r}=\sum_{s}\left[\beta \sum_{t \in N_{s}} \delta\left(y_{s}, y_{t}\right)\right]
$$

where $y_{s}$ and $y_{t}$ are the respective class of pixels $s$ and $t$ inside the clique, and $\delta\left(y_{s} ; y_{t}\right)=-1$ if $y_{s}=y_{t}$ and $\delta\left(y_{s} ; y_{t}\right)=1$ if $y s \neq y_{t} . \beta$ is a constant. In the absence of training samples to determine the labels of the pixels of the clique, these are initially randomly determined and gradually stabilize by iteration.

In equation 2, $\sigma$ is a parameter that sets the proportions of the relative contribution of $E_{r}$ and $E_{f}$ within $E$. The adaptation of [31] makes $\sigma$ iteratively change the weighting between the spectral (global) and spatial (local) components; early iterations favor the spectral component and increased iterations gradually increase the weight on the spatial component.

Three parameters need to be specified for the classification to take place: 1) the number of classes, 2) the number of iterations and 3) a mask to limit the classification (this can ultimately be the whole image). In our case, the classification was binary ("vereda" and "non-vereda") and the number of iterations varied between 50 and 120 with increments of ten. The mask consisted of a buffer of $1000 \mathrm{~m}$ on both side of the hydrographic network to include all the veredas which are no larger than about 500 $\mathrm{m}$ in the region. Eighty iterations were sufficient for the result to converge and this number of iterations was used in all tests.

\subsection{Classification of the veredas type}

An image dataset was created by joining the three ASTER VNIR bands, three of the six SWIR bands (bands 2, 3 and 5 had the least visually noticeable noise) and the four Radarsat- 1 scenes that were previously filtered using a $3 \times 3$ median filter to reduce speckle noise. The set was given a standard resolution cell of $15 \times 15$. Pixels of the SWIR bands were simply duplicated while the Radarsat- 1 scenes were resampled by bilinear interpolation. In many cases we observed in the field that the different 
vegetation types were almost systematically arranged in parallel strips along the hydrographic network but that their width was often smaller than 20 meters. To overcome the mismatch between image resolution $(15 \mathrm{~m})$ and target width, some classes with similar characteristics had to be merged. The resulting classes were: 1) dense wooded savanna, 2) sparse wooded savanna, 3) grass (or meadow), 4) shrub, 5) riparian forest, 6) sandy soil with little vegetation and 7) open water.

Classification algorithms can be grouped into parametric and non-parametric. The latter have the advantage of not assuming a distribution function (e.g. Gaussian or Gibbs) and are less restrictive regarding the number and location of samples for statistical training. Both the Fisher criteria and the Mahanalobis distance were tested. The Fisher linear criteria classifier uses the training data to construct a linear function that combines all the features (or bands) to maximize the variance between classes and minimize the variance within class [41].The Mahanalobis distance [42] is used to measure the distance between a single observation $\mathbf{x}$ and a class distribution $(\mu ; \Sigma)$. Although it uses the mean and covariance matrix, unlike the maximum likelihood it does not assume a Gaussian distribution.

Both the Fisher criteria and the Mahanalobis distance were tested with and without first applying a segmentation routine; an approach called ECHO (Extraction and Classification of Homogeneous Objects) [43]. The classification tests presented here were produced with the Purdue/NASA MultiSpec software package. The MultiSpec classification scheme can classify any combination of the training areas, testing areas and/or the entire image and reports the results with a wide range of statistics. [43] give a complete description of the MultiSpec package. A separate set of ground truth data that was not used for training the algorithm, was randomly selected to test the accuracy of the classification results.

\subsection{Statistical inference}

Because the Kappa statistic has been known to overestimate the degree of chance agreement [44] and has generated a fair amount of controversy, it was not used for comparing the results. Instead, the $\mathrm{McNemar}$ test was used to compare the results since the same samples were used for all classification tests and were not therefore independent as would require a Kappa difference test [45]. The McNemar test computes a $Z$ statistic from a two by two matrix based on correctly and incorrectly classified pixels in both classifications as follows:

$$
Z=\frac{f 12-f 21}{\sqrt{f 12+f 21}}
$$

where $f 12$ represent the pixels that are correctly classified in the first classification and incorrectly classified in the second classification and $f 21$ represents the opposite situation. $Z$ values of 1.96 and 2.58 were considered for the $95 \%$ and $99 \%$ levels of confidence respectively.

\section{Results and Discussion}

\subsection{Delineating veredas}

The four Radarsat-1 images were successfully segmented and labeled. Because of its higher dielectric constant and high scattering capacity, a vereda tend to be brighter than its surrounding. The 
soil moisture is considered a significant component responsible for the increase in the dielectric constant. Table 2 shows the gravimetric moisture measured in the soil of the main vegetation types during the dry season.

Table 2. Summary of gravimetric soil moisture data collected in the study area.

\begin{tabular}{l|c|c}
\hline \multicolumn{1}{c|}{ Vegetation type } & Number of samples & Gravimetric moisture \\
\hline Wooded savanna & 4 & $4.41 \%$ \\
Grassland/wet meadows & 9 & $8.91 \%$ \\
Riparian forest & 9 & $59.54 \%$ \\
\hline
\end{tabular}

The moisture gradient is quite neatly expressed especially for the riparian forest (soil samples from the shrub type were excluded because only two valid samples were processed and results were inconclusive). For this reason, the class with the highest backscattering average was labeled as "vereda" leaving the remaining class as "non-vereda". Only the segments directly connected to the hydrographic network were kept using a "contamination" process; the pixels belonging to both the vereda segments and the stream were marked and then all (four-) connected pixels to these also received an approval mark. The remaining pixels were attributed the non-vereda class. This process made sure that other regions such as swampy pools were not wrongly classified as vereda. Figure 5 shows the classification results for the four Radarsat-1 images. The first observation is that despite a relatively low visual contrast and a significant presence of noise, the MAMSEG algorithm did extract strips of higher backscattering, perhaps even better than the naked eye could have done. Eliminating the non-connected segments further improve the visual results. Before considering ground truth and the contingency table, a number of visual observations are inferred below.

- Eliminating unconnected pixels from the results using the hydrographic network and the "contamination" approach is a necessary step.

- The April (end of the rain season) images offer better visual contrast and visually more consistent results.

- The lower incidence angle (S2), prioritizing direct backscattering (as opposed to volumetric) tends to produce more consistent results in terms of continuity (less gaps) and width of the veredas. Because veredas vary in width and many sections are quite narrow, the volumetric backscatter does not always produce a significant contrast with the surrounding savanna vegetation.

- Veredas near the headwaters are more difficult to detect probably because of their narrower width and less saturated soils. Soils in the headwater veredas were found to be generally dryer therefore the dielectric constant should be lower.

- Combining higher incidence angle (S6) and dry season (September) produce the worse visual results. This observation supports the second and third statement and veredas are much harder to detect (even visually) in the September S6 image.

The difference in moisture suggests that, in terms of soil, grassland is more likely to be associated to the savanna than it is to the riparian forest. For this reason, two versions of the confusion matrix were built (Tables 3 and 4). 
Figure 5. SAR images (left), classification results obtained with the MAMSEG algorithm for the two periods and the two incidence angles using 80 iterations (center) and classification results after they have been "cleaned" using the stream network and the contamination algorithm (right).
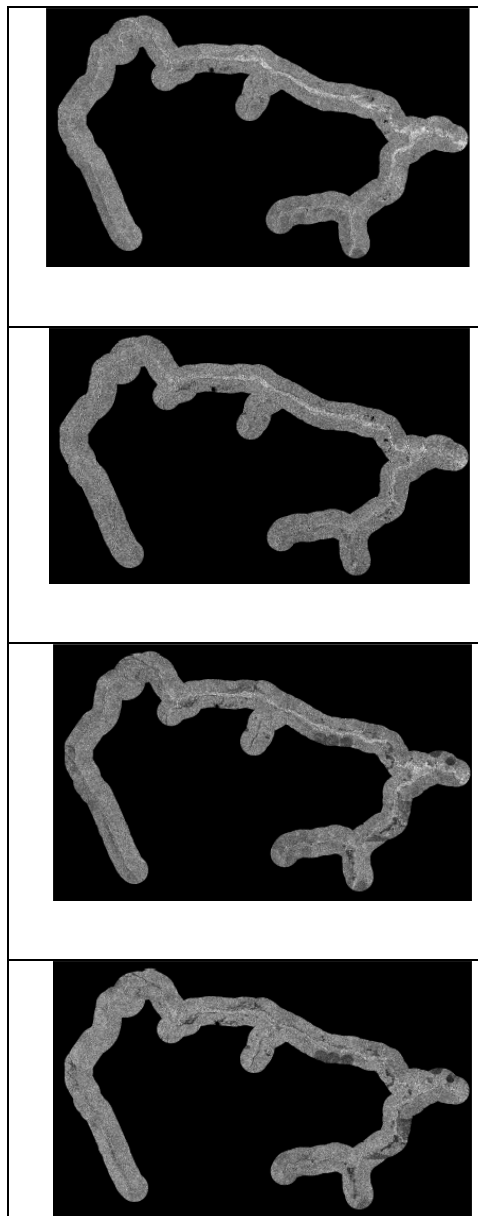

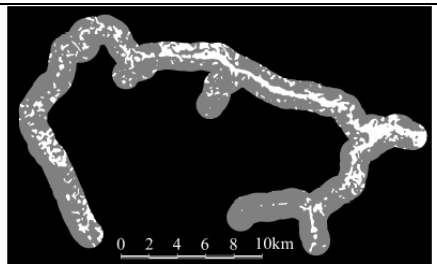

(a) April S2

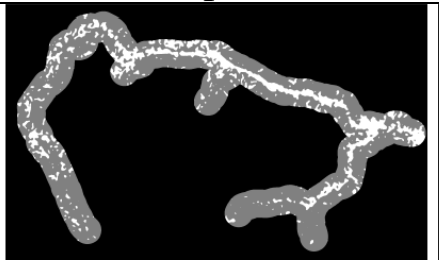

(b) April S6

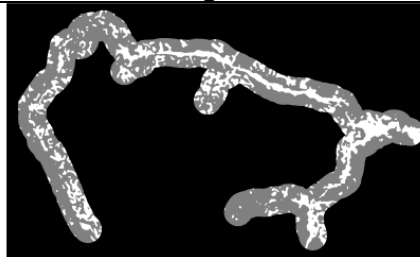

(c) September S2

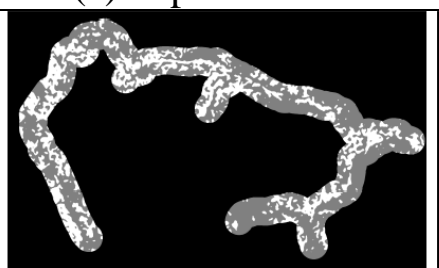

(d) September S6
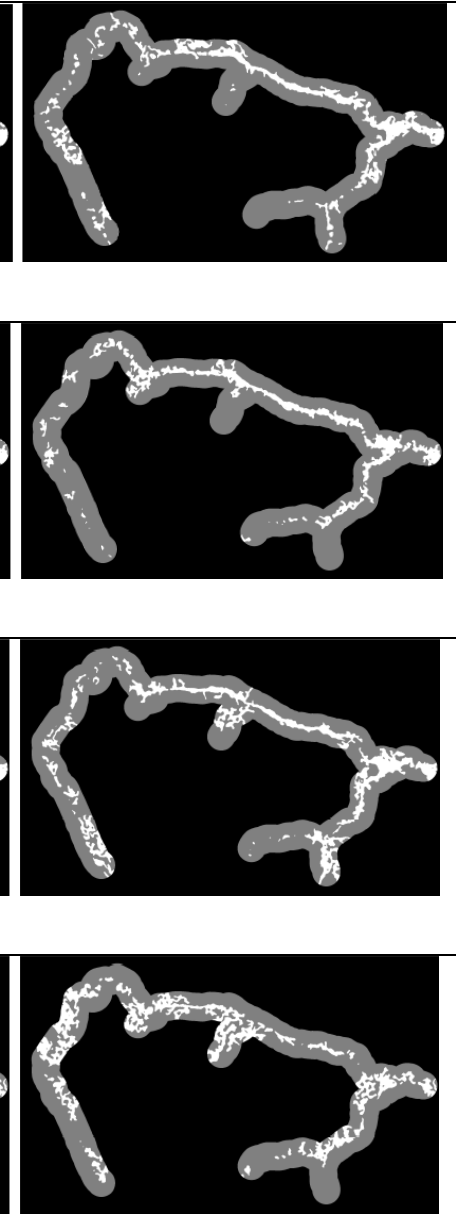

In Table 3, the wet meadow (grasses) type has been kept as part of the vereda class since, strictly speaking, this strata is part of the vereda complex. However, because it was not clear if the grassland would be captured as being part of the strip with higher backscatter response, a second version of the contingency matrix was made excluding it from the vereda class and incorporating it as non-vereda (Table 4). The wet meadow type usually occupies the transition zone between the (dry) savanna and the (wet) palm swamp so that its state changes from saturated to dry during the year. Since April represents the end of the wet season, the soil is not completely saturated and its dielectric constant is probably less than at high rain season.

Table 3 confirms the observation made above that the combination of "wet" season image and the low incidence angle shows better potential for delineating the vereda complex but the difference of $1.95 \%$ to the second best (September S2) is marginal. Like for Table 3, Table 4 confirms that the April S2 image yields the best results for delineating veredas. Comparing Tables 3 and 4 leads to the consistent observation that excluding the grassland leads to better results in all cases. 
Table 3. Confusion matrices and overall success for the classification of the four Radarsat1 images into vereda (including grassland) and non-vereda.

\begin{tabular}{lccc}
\hline & $\begin{array}{c}\text { Vereda pixels } \\
(489)\end{array}$ & $\begin{array}{c}\text { Non-vereda pixels } \\
(589)\end{array}$ & $\begin{array}{c}\text { Total } \\
(1078)\end{array}$ \\
\hline April S2 & & Overall: & $\mathbf{6 4 . 1 \%}$ \\
vereda & 236 & 134 & 370 \\
non-vereda & 253 & 455 & 708 \\
\hline April S6 & & Overall: & $\mathbf{6 1 . 5 \%}$ \\
vereda & 271 & 197 & 468 \\
non-vereda & 218 & 392 & 610 \\
\hline Sept. S2 & & Overall: & $\mathbf{6 2 . 2 \%}$ \\
vereda & 280 & 199 & 479 \\
non-vereda & 209 & 390 & 599 \\
\hline Sept. S6 & & Overall: & $\mathbf{6 2 . 0 \%}$ \\
vereda & 178 & 99 & 277 \\
non-vereda & 311 & 490 & 801 \\
\hline
\end{tabular}

Table 4. Confusion matrices and overall success for the classification of the four Radarsat1 images into vereda (excluding grassland) and non-vereda.

\begin{tabular}{lccc}
\hline & $\begin{array}{c}\text { Vereda pixels } \\
(405)\end{array}$ & Non-vereda pixels (672) & $\begin{array}{c}\text { Total } \\
(1077)\end{array}$ \\
\hline April S2 & & Overall: & $\mathbf{6 9 . 2 \%}$ \\
vereda & 222 & 149 & 371 \\
non-vereda & 183 & 523 & 706 \\
\hline April S6 & & Overall: & $\mathbf{6 4 . 7 \%}$ \\
vereda & 248 & 223 & 471 \\
non-vereda & 157 & 449 & 606 \\
\hline Sept. S2 & & Overall: & $\mathbf{6 5 . 3 \%}$ \\
vereda & 255 & 224 & 479 \\
non-vereda & 209 & 390 & 599 \\
\hline Sept. S6 & & Overall: & $\mathbf{6 6 . 1 \%}$ \\
vereda & 159 & 119 & 278 \\
non-vereda & 246 & 553 & 799 \\
\hline
\end{tabular}

Table 5 shows the $\mathrm{Z}$ statistic computed to compare all the results of Tables 3 and 4 . At a $95 \%$ level of confidence, none of the differences between results including grassland type in the vereda complex was found to be significant. However, if the grassland type is excluded, than the results from the April S2 image are significantly better than the results from all other images.

The same McNemar test was applied to assess if there is a significant difference between including grassland (Table 3) and excluding them (Table 4). Z statistics of 6.110, 3.976, 3.710 and 4.939 were 
obtained for April S2, April S6, September S2 and September S6 respectively which are all significant at $99 \%(\mathrm{Z}=2.58)$.

Table 5. The McNemar test: $\mathrm{Z}$ statistics and significance of Radarsat image classification differences for the reference set including (left) and excluding (right) the grassland type (values in bold are significant at $95 \%, \mathrm{Z}=1.96$ ).

\begin{tabular}{l|ccc|ccc}
\hline & \multicolumn{3}{|c|}{ Grassland included } & \multicolumn{3}{c}{ Grassland excluded } \\
& April S6 & Sept. S2 & Sept. S6 & April S6 & Sept. S2 & Sept. S6 \\
\hline April S2 & 1.1826 & 0.8705 & 1.5416 & $\mathbf{2 . 3 5 7 0}$ & $\mathbf{2 . 3 4 3 8}$ & $\mathbf{2 . 2 1 5 6}$ \\
April S6 & - & 0.4048 & 0.2941 & - & 0.2882 & 0.2349 \\
Sept. S2 & - & - & 0.7047 & - & - & 0.0586 \\
\hline
\end{tabular}

\subsection{Classifying the different types}

The combination of the Mahanalobis distance classifier and the ECHO routine produced systematically higher classification success, and since the choice of classifier is outside the scope of this article, only these results are presented here. In order to evaluate the contribution of the different ASTER bands and Radarsat scenes, a "knock-out" approach was used as a preliminary feature selection scheme [46]. The "knock-out" approach consists in progressively eliminating the least useful features by successive classifications until only one is left. Since finding the best subset of features is a combinational problem (10 features represent 1023 different combinations), the "knock-out" approach is a very effective suboptimal method for ranking the features in the image set (only 55 or [10(10+1)/2] combinations need to be tested).

The result of the "knock-out" method of feature ranking is presented in Table 6. The fact that the three SWIR bands are the least useful was partly expected since its ground resolution is the coarsest and at least three of the classes are expected to have a narrow configuration. The two April Radarsat-1 scenes (S2 and S6) come in third and fourth place above the two September scenes suggesting that April (the end of the wet season with moist vegetation and soils) is more appropriate for separating the different types. The fact that the red band (VNIR 2) is ranked lower than the two SAR (April) scenes was rather surprising but it should be noted that the difference in performance with these three features is very small (see Kappa results in Table 6).

Based on these ranking results, different classifications were tested using different subset of features from the image set and are presented in decreasing order of performance (based on the Kappa results of the validation set) in Table 7. The VNIR achieved a higher score with an overall success of 78,8\% followed closely by the subset integrating the VNIR and the two Radarsat-1 scenes from April. The Radarsat-1 scenes do not bring any improvement and the results remain not significantly different. The inclusion of a SWIR band (3 which ranked best) only contributes to decrease the overall accuracy. As for the attempt of classifying the types with only the four Radarsat scenes, the overall success was only $50,8 \%$ which supports the statement made earlier that single phase/frequency SAR is usually not sufficient to discriminate between vegetation types. 
Table 6. Feature ranking results obtained from the "knock-out" approach.

\begin{tabular}{|c|c|c|c|}
\hline Rank & Feature & $\operatorname{Kappa}(\hat{\boldsymbol{k}})$ & Feature used (by rank) \\
\hline 1 (most useful) & VNIR 1 (green) & $61,1 \%$ & 1 \\
\hline 2 & VNIR 3 (near infrared) & $68,9 \%$ & 12 \\
\hline 3 & SAR April S2 & $71,0 \%$ & 123 \\
\hline 4 & SAR April S6 & $72,2 \%$ & 1234 \\
\hline 5 & VNIR 2 (red) & $71,8 \%$ & 12345 \\
\hline 6 & SAR September S6 & $67,4 \%$ & 123456 \\
\hline 7 & SAR September S2 & $61,9 \%$ & 1234567 \\
\hline 8 & SWIR 3 & $59,5 \%$ & 12345678 \\
\hline 9 & SWIR 2 & $59,1 \%$ & 123456789 \\
\hline 10 (least useful) & SWIR 5 & $56,6 \%$ & 12345678910 \\
\hline
\end{tabular}

The results of VNIR-only classification are shown in Figure 6 and in Table 7. This classification corresponds to all the classes described earlier in Table 1 . The overall performance of $78.8 \%$ is good considering the marginal spatial resolution and the narrow nature of three of the classes. Most of the confusion between these classes are concentrated between shrub and grassland, shrub and riparian forest, sparse and dense savanna. These classification errors can be mostly attributed to training and test pixels with mixed vegetation cover which was often unavoidable because of the narrow nature of these vegetation types. In other words, resolution cells in the order of five to ten meters would have been preferable but might also have caused other problems such as increase data variance and texture related problems.

\subsection{Comparing the Results}

In order to assess the effectiveness of the unsupervised classification of the Radarsat-1 scenes using the MRF-based segmentation, the results were compared with the ASTER VNIR supervised classification (types). The comparison was done by intersecting both classification in the following manner:

$$
\text { if } S A R_{\text {class }}=\text { veredas then } A S T E R_{\text {class }} \text { else null }
$$

The results of these crossing operations were then compared with the classification of the different types given that the same $2,000 \mathrm{~m}$ buffer was applied to the classified image. Table 8 reveals that although a large proportion of the veredas were captured by the approach using the MAMSEG algorithm, it also captured large areas of savanna that do not belong to the vereda class, especially in the two September images. It is our understanding that these "artifacts" were created by the lack of clear contrast between the veredas and the other vegetation covers. A strong correspondance between the riparian forest type and what was classified as vereda in the SAR image is clearly shown for all four SAR results with an average percentage of $74.2 \%$ of the riparian forest being captured by the approach. Even when considering the accuracy of the riparian forest class is around $84 \%$, these results can be regarded as reasonable. A visual comparison between any of the SAR results (Figure 5 and the ASTER classification in Figure 6) reveals that the headwater sections were not well recognized and are 
characterized by numerous gaps attributed to the narrowness of the veredas in these regions. These areas of veredas are also drier in comparison with downstream wider areas. The grassland was only partially captured confirming our initial observation that these regions might not be well captured at least in their dry portion.

Table 7. Classification accuracy obtained from the different subset of features for the classification of vegetation types of the veredas and surroundings ( $\mathrm{P} \%$ represents the producer's accuracy and U\% the user's).

\begin{tabular}{|c|c|c|c|c|c|c|c|c|c|}
\hline \multicolumn{2}{|l|}{ Samples } & \multicolumn{2}{|c|}{ VNIR } & \multicolumn{2}{|c|}{$\begin{array}{l}\text { VNIR and } \\
\operatorname{SWIR}(3)\end{array}$} & \multicolumn{2}{|c|}{$\begin{array}{c}\text { VNIR and } \\
\text { SAR (April) }\end{array}$} & \multicolumn{2}{|c|}{ SAR (all 4) } \\
\hline Class & $(\mathrm{n})$ & $\mathrm{P} \%$ & $\mathrm{U} \%$ & $\mathrm{P} \%$ & $\mathrm{U} \%$ & $\mathrm{P} \%$ & $\mathrm{U} \%$ & $\mathrm{P} \%$ & $\mathrm{U} \%$ \\
\hline Grassland & 48 & 77.1 & 64.9 & 68.8 & 57.9 & 68.8 & 62.3 & 62.5 & 30.9 \\
\hline Shrubland & 60 & 21.7 & 56.5 & 23.3 & 60.9 & 15.0 & 69.2 & 6.7 & 5.8 \\
\hline Riparian forest & 176 & 84.1 & 84.1 & 84.1 & 69.5 & 83.5 & 87.5 & 84.7 & 87.1 \\
\hline Savanna (sparse) & 50 & 78.0 & 68.4 & 28.0 & 41.2 & 96.0 & 69.6 & 50.0 & 32.9 \\
\hline Savanna (dense) & 180 & 87.8 & 81.9 & 67.2 & 77.1 & 88.9 & 83.3 & 39.4 & 54.2 \\
\hline Bare soil (sand) & 42 & 90.5 & 76.0 & 90.5 & 52.8 & 92.9 & 57.4 & 4.8 & 9.1 \\
\hline Open water & 23 & 100.0 & 100.0 & 100.0 & 100.0 & 69.6 & 100.0 & 56.5 & 100.0 \\
\hline $\begin{array}{l}\text { Overall success } \\
\text { Kappa }(\hat{\boldsymbol{k}})\end{array}$ & & \multicolumn{2}{|c|}{$\begin{array}{l}78.8 \\
75.2\end{array}$} & \multicolumn{2}{|c|}{$\begin{array}{l}67.5 \\
58.2\end{array}$} & \multicolumn{2}{|c|}{$\begin{array}{l}78.1 \\
71.8\end{array}$} & \multicolumn{2}{|c|}{$\begin{array}{l}50.8 \\
42.8\end{array}$} \\
\hline
\end{tabular}

Table 8. Percentage of the vegetation cover captured by the unsupervised classification/labeling process of each of the four Radarsat-1 images (based on the ASTER VNIR classification and the 2,000 $\mathrm{m}$ buffer).

\begin{tabular}{l|cccc}
\hline Vegetation & \multicolumn{2}{c}{ April } & \multicolumn{2}{c}{ September } \\
& S2\% & S6\% & S2\% & S6\% \\
\hline Grassland & 38.2 & 30.8 & 31.6 & 17.7 \\
Shrub & 28.6 & 37.4 & 30.3 & 31.8 \\
Riparian forest & 76.4 & 77.7 & 78.0 & 64.7 \\
Sparse savanna & 11.3 & 11.4 & 9.8 & 9.2 \\
& & & & \\
Dense savanna & 13.6 & 10.4 & 20.5 & 28.0 \\
Bare soil & 14.9 & 7.5 & 8.0 & 4.8 \\
\hline
\end{tabular}


Figure 6. Results obtained from the classification of the vegetation types a) with the ASTER image (VNIR only) and b) with the four Radarsat-1 scenes combined.

(a)

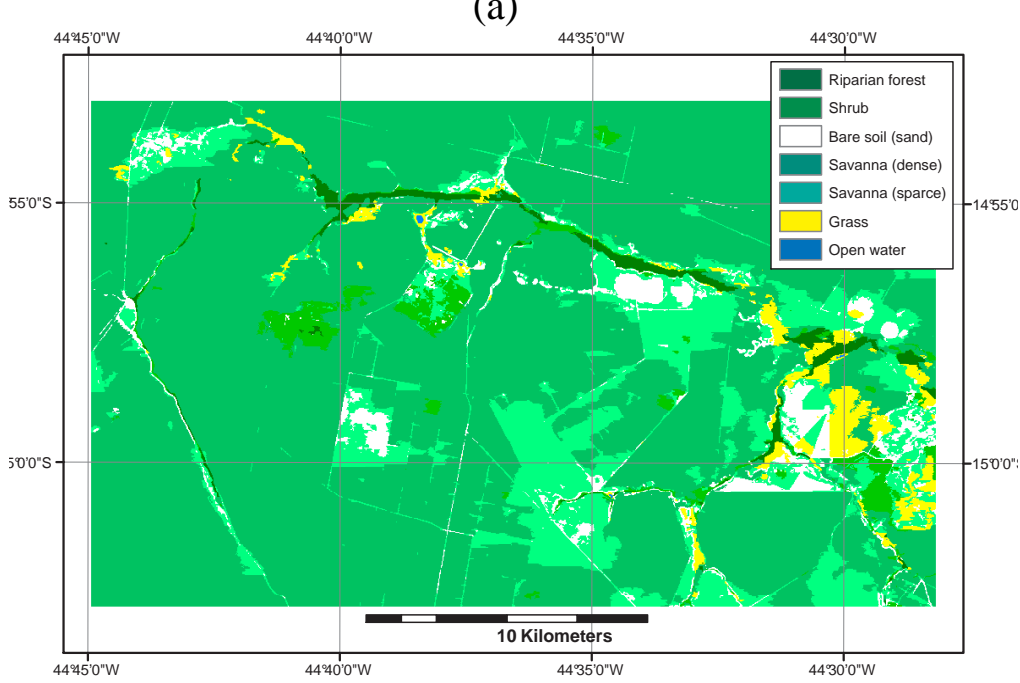

(b)

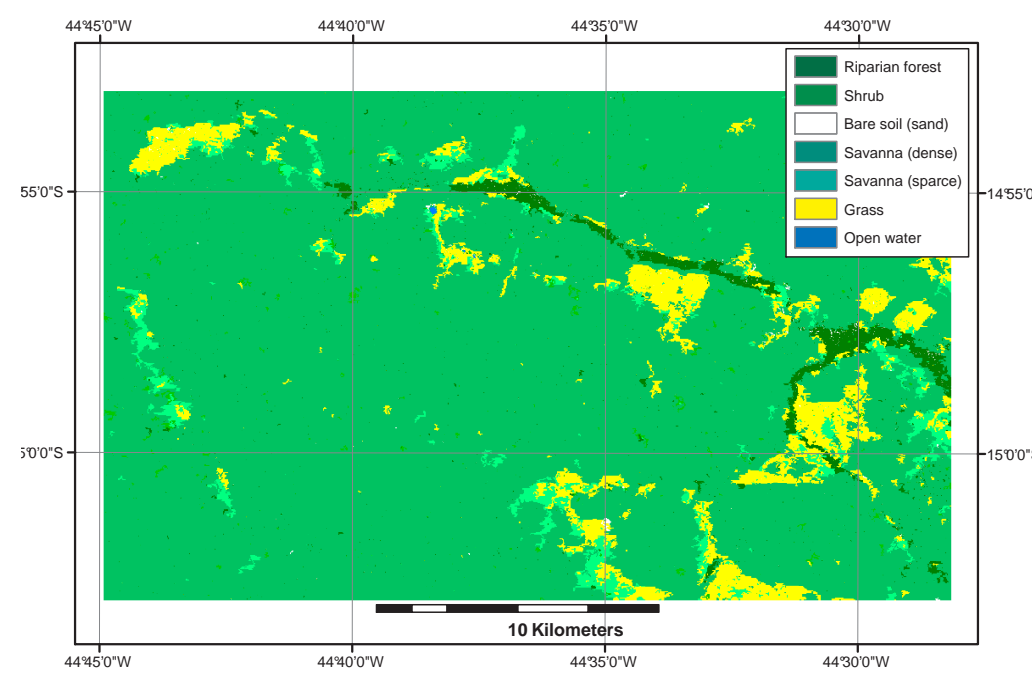

\section{Conclusions}

An experimental evaluation of synthetic aperture radar (Radarsat-1) and optical (ASTER) data for delineating and characterizing veredas has been concluded in this paper and the results suggest that both data types show good potential providing that appropriate classification tools are used. An original unsupervised algorithm based on Markov random fields (MAMSEG) proved better than conventional pixel-based classification for delineating veredas using SAR data if the processing is restricted to a buffer zone following the hydrographic network.

For the SAR-based delineation, the results suggest that images acquired during or at the end of the rain season with a low incidence angle tend to yield better results. The advantage of using the hydrographic network buffering and the MAMSEG algorithm is that no ground truth data is required 
prior to the classification. The study also gives an insight on the mechanisms ruling the relation between the veredas types and SAR backscattering response.

The classification of the vegetation types revealed that the SAR-based delineation of the veredas left important gaps, but that the riparian forest portion was generally captured unless it lies near the headwaters (dryer soil) or has a very narrow width. The VNIR instrument of the ASTER image has a marginal ground resolution for capturing the different vegetation types of the veredas that are sometimes narrower than a single pixel but provided reasonable accuracy $(\hat{\boldsymbol{k}} \approx 75 \%$ ) for mapping the main vegetation forms.

Veredas are very important wetland complexes for the cerrado biome and various government agencies have already outlined the need for mapping their extent and state. We believe that the automatic classification of SAR images (Radarsat or other C-band SAR imagery) is an efficient means of providing a rough evaluation of their extent. Fine resolution optical data like ASTER could then be used to characterize their type. More precise solutions would almost unavoidably involve highresolution data (e.g. Ikonos, Quickbird) at a much higher cost.

\section{Acknowledgements}

The authors are thankful to the Canadian Space Agency (CSA; http://www.csa.gc.ca) for providing the RADARSAT-1 data (all RADARSAT images (C) CSA - http://www.space/gc/ca) through the Data for Research Use (DRU) project. The authors would also like to thank the Instituto Estadual de Florestas (IEF) of Minas Gerais for their logistic support and especially Professor Célio Murilo de Carvalho Valle for his encouragements and for organizing the helicopter flights. Finally, we are thankful to the anonymous reviewers who have helped improve the article with pertinent comments.

\section{References}

1. Mitsch, W.; Gosselink, J. In Wetlands. John Wiley and Sons: New York, NY, USA, 2000.

2. Roulet, N.T. Peatlands, carbon storage, greenhouse gases and the Kyoto Protocol: prospects and significance for Canada. Wetlands 2000, 20, 605-615.

3. Drummond, G.M.; Martins, C.S.; Machado, A.B.M.; Sebaio, F.A.; Antonini, Y. In Biodiversidade em Minas Gerais: um atlas para sua conservação. Fundação Biodiversitas: Belo Horizonte, Brazil, 2005.

4. Boaventura, R. S. Preservação da veredas - síntese. In Proceedings of the $2^{\text {nd }}$ latin-american meeting: human-environment relationship, Belo Horizonte, Brazil, 1988; pp. 109-122.

5. Melo, D.R. As veredas nos planaltos do Noroeste Mineiro; caracterização pedológica e os aspectos morfológicos e evolutivos. Master's thesis, Universidade Estadual Paulista: São Paulo, Brazil, 1992.

6. Ratter, J.A.; Ribeiro, J.F.; Bridgewater, S. The Brazilian cerrado vegetation and threats to its biodiversity. Ann. Bot. 1997, 80, 223-230.

7. Baker, C.; Lawrence, R.; Montagne, C.; Patten, D. Mapping wetlands and riparian areas using Landsat ETM+ imagery and decision-tree-based models. Wetlands 2006, 26, 465-474. 
8. Melack, J.M. Tropical freshwater wetlands, In Manual of Remote Sensing, vol. 4: Remote Sensing for Natural Management and Environmental Monitoring. JohnWiley and Sons: Hoboken, NJ, USA, 2004; pp. 319-343.

9. O'Connell, M.J. Detecting, measuring and reversing changes to wetlands. Wetlands Ecol. Manag. 2003, 11, 397-401.

10. Coleman, T.L.; Fletcher, R.F.; Clerke, W.H. Spectral differentiation of wetland habitats within the Conecuh National Forest. In Proceedings of the Fourth Forest Service Remote Sensing Applications Conference, Orlando, Florida, USA, April 1992. American Society for Photogrammetry and Remote Sensing, pp. 64-74.

11. Hewitt, M. Synoptic inventory of riparian ecoystems: The utility of Landsat Thematic Mapper data. For. Ecol. Manag. 1990, 33/34, 605-620.

12. Johansen, K.; Phinn, S. Mapping structural parameters and species composition of ripirian using IKONOS and Landsat ETM+ data in australian tropical savannahs. Photogramm. Eng. Remote Sens. 2006, 72, 71-80.

13. Gomes, M.F.; Maillard, P. Comportement spectral saisonnier des formations végétales semi-arides dans la vallée de la rivière Peruaçu - Minas Gerais, Brésil. In Proceedings of the XXV Canadian Remote Sensing Symposium, Montreal, QC, Canada, October 2003. Canadian Aeronautics and Space Institute,

14. Kasischke, E.S.; Melack, J.M.; Dobson, M.G. The use of imaging radars for ecological applications - a review. Remote Sens. Environ. 1997, 59, 141-156.

15. Leckie, D.G.; Ranson, K.J. Forestry applications using imaging radar, In Manual of remote sensing, $3^{\text {rd }}$ edition; John Wiley and Sons: New York, NY, 1998; volume 2, pp. 435-509.

16. Raney, R. Radar fundamentals: technical perspective, In Manual of Remote Sensing, Principles and Aplications of Imaging Radar. John Wiley and Sons, New York, NY, USA, 1998; volume 2, pp. $9-130$.

17. Ulaby, F.; Sarabandi, K.; McDonald, K.; Whitt, M.; Dobson, M. In Microwave Remote Sensing, Active and Passive, volume I: Microwave Remote Sensing Fundamentals and Radiometry. Addison- Wesley, Reading: MA, USA, 1981.

18. Freeman, A. A three-component scattering model for polarimetric SAR data. IEEE Trans. Geosci. Remote Sens. 1998, 36, 963-973.

19. Townsend, P.A. Mapping seasonal flooding in forested wetlands using multi-temporal RADARSAT SAR. Photogramm. Eng. Remote Sens. 2001, 67, 857-864.

20. Lo, C.P. Applications of imaging radar to land use and land cover mapping, In Manual of Remote Sensing, vol. 2 Principles and Aplications of Imaging Radar. John Wiley and Sons: New York, NY, USA, 1998; pp. 705-732.

21. Haack, B.N.; Herold, N.D.; Bechdol, M.A. Radar and optical data integration for landuse/landcover mapping. Photogramm. Eng. Remote Sens. 2000, 66, 709-716.

22. Huang, H.; Legarsky, J.; Othman, M. Land-cover classification using Radarsat-1 and Landsat imagery for St. Louis, Missouri. Photogramm. Eng. Remote Sens. 2007, 73, 37- 43.

23. Franklin, S.E. Remote Sensing for Sustainable Forest Management. Lewis Publishers: Boca Raton, Florida, USA, 2001. 
24. Hess, L.L.; Melack, J.M.; Simonett, D.S. Radar detection of flooding beneath the forest canopy - a review. IEEE Trans. Geosci. Remote Sens. 1990, 29, 545-554.

25. Hess, L.L.; Melack, J.M. Mapping wetland hydrology and vegetation with synthetic aperture radar. Int. J. Ecol.Environ. Sci. 1994, 20, 197-205.

26. Parmuchi, M.G.; Karszenbaum, H.; Kandus, P. Mapping wetlands using multi-temporal RADARSAT- 1 data and a decision-based classifier. Can. J. Remote Sens. 2002, 28, 175-186.

27. Kovacs, J.M.; Vanderberg, C.V.; Flores-Verdugo, F. Assessing fine beam RADARSAT-1 backscatter from a white mangrove (Laguncularia racemosa (Gaertner)) canopy. Wetlands Ecol.Manag. 2006, 14, 401-408.

28. McCabe, M.F.; Wood, E.F. Scale influences on the remote estimation of evapotranspiration using multiple satellite sensors. Remote Sens. Environ. 2006, 105, 271-285.

29. Blaes, X.; Vanhalleb, L.; Defourny, P. Efficiency of crop identification based on optical and SAR image time series. Remote Sens. Environ. 2005, 96, 352-365.

30. Hill, M.J.; Ticehurst, C.J.; Lee, J.S.; Grunes, M.R.; Donald, G.E.; Henry, D. Integration of optical and radar classifications for mapping pasture type in Western Australia. IEEE Trans. Geosci. Remote Sens. 2005, 43, 1665-1681.

31. Deng, H.; Clausi, D.A. Unsupervised segmentation of synthetic aperture radar sea ice imagery using a novel Markov random field models. IEEE Trans. Geosci. Remote Sens., 43, 528-538.

32. Maillard, P.; Clausi, D.A.; Deng, H. Operational map-guided classification of sar sea ice imagery. IEEE Trans. Geosci. Remote Sens. 2005, 43, 2940-2951.

33. Alencar-Silva, T.; Maillard, P. Delineation of palm swamps using segmentation of Radarsat data and spatial knowledge. In Proceedings of the ISPRS Annual Conference, Enschede, The Netherland, May 2006.

34. Nimer, E.; Brandão, A.M.P.M. In Balanço Hídrico e Clima da Região dos Cerrados. Instituto Brasileiro de Geografia e Estatística - IBGE: Rio de Janeiro, Brazil, 1989.

35. Töyrä, J.; Pietroniro, A.; Martz, L.W. Multisensor hydrologic assessment of a freshwater wetland. Remote Sens. Environ. 2001, 75, 162-173.

36. Townsend, P.A. Estimating forest structure in wetlands using multitemporal SAR. Remote Sens. Environ. 2002, 79, 288-304.

37. Arai, K.; Tonooka, H. Radiometric performance evaluation of ASTER VNIR, SWIR, and TIR. IEEE Trans. Geosci. Remote Sens.2005, 43, 2725-2732.

38. Li, S.Z. In Markov Random Field Modeling in Computer Vision. Springer-Verlag: New York, NY, USA, 1995.

39. Tso, B.; Mather, P. In Classification Methods for Remotely Sensed Data. Taylor and Francis: London, England, 2001.

40. Geman, D.; Geman, S.; Graffigne, C.; Dong, P. Boundary detection by constrained optimization. IEEE Trans. Pattern Anal. Machine Intell. 1990, 12, 609-628.

41. Duda, R.O.; Hart, P.E. In Pattern Classification and Scene Analysis. Wiley-Interscience: New York, NY, USA, 2000.

42. Duda, R.; Hart, P.; Stork, D. In Pattern Classification. John Wiley \& Sons: New York, NY, USA, 2001. 
43. Biehl, L.; Landgrebe, D. Multispec - a tool for multispectral - hyperspectral image data analysis. Comput. Geosci. 2002, 28, 1153-1159.

44. Foody, G.M. On the compensation for chance agreement in image classification accuracy assessment. Photogramm. Eng. Remote Sens. 1992, 58, 1459-1460.

45. Foody, G.M. Thematic map comparison: evaluating the statistical significance of differences in classification accuracy. Photogramm. Eng. Remote Sens 2004, 70, 627-633.

46. Sambur, M.R. Selection of accoustic features for speaker identification. IEEE Trans. Accoust. Speech Signal Process. 1975, ASSP 23, 176-182.

(C) 2008 by the authors; licensee Molecular Diversity Preservation International, Basel, Switzerland. This article is an open-access article distributed under the terms and conditions of the Creative Commons Attribution license (http://creativecommons.org/licenses/by/3.0/). 